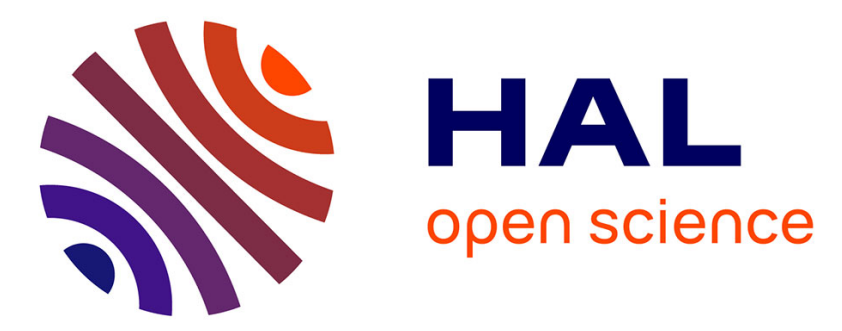

\title{
Joint application of geophysical methods and Direct Push-soil gas surveys for the improved delineation of buried fault zones
}

Claudia Schütze, Thomas Vienken, Ulrike Werban, Peter Dietrich, Anthony Finizola, Carsten Leven

\section{To cite this version:}

Claudia Schütze, Thomas Vienken, Ulrike Werban, Peter Dietrich, Anthony Finizola, et al.. Joint application of geophysical methods and Direct Push-soil gas surveys for the improved delineation of buried fault zones. Journal of Applied Geophysics, 2012, 82, pp.129-136. 10.1016/j.jappgeo.2012.03.002 . hal-01148223

\section{HAL Id: hal-01148223 \\ https://hal.science/hal-01148223}

Submitted on 3 Nov 2016

HAL is a multi-disciplinary open access archive for the deposit and dissemination of scientific research documents, whether they are published or not. The documents may come from teaching and research institutions in France or abroad, or from public or private research centers.
L'archive ouverte pluridisciplinaire HAL, est destinée au dépôt et à la diffusion de documents scientifiques de niveau recherche, publiés ou non, émanant des établissements d'enseignement et de recherche français ou étrangers, des laboratoires publics ou privés. 


\title{
Joint application of geophysical methods and Direct Push-soil gas surveys for the improved delineation of buried fault zones
}

\author{
Claudia Schütze ${ }^{\text {a,* }}$, Thomas Vienken ${ }^{\text {a, } 1}$, Ulrike Werban ${ }^{\text {a, }}$, Peter Dietrich ${ }^{\text {a, } 3}$, \\ Anthony Finizola ${ }^{b, 4}$, Carsten Leven ${ }^{c, 5}$ \\ ${ }^{a}$ UFZ-Helmholtz Centre for Environmental Research, Dept. Monitoring and Exploration Technologies, Permoser Str. 15 D-04318 Leipzig, \\ Germany \\ b Laboratoire GéoSciences Réunion, Université de la Réunion, Institut de Physique du Globe de Paris, Sorbonne Paris-Cité, CNRS UMR \\ 7154, 15 rue René Cassin, 97715 Saint-Denis cedex 9,La Réunion, Indian Ocean, France \\ ${ }^{\mathrm{C}}$ University of Tübingen, Center for Applied Geoscience, Hydrogeology, Sigwartstr. 10 D-72076 Tübingen, Germany
}

This study provides an example of fault structure delineation using both geophysical measurements and soil-gas surveys. Seismic refraction and electrical resistivity tomography investigations were performed in com-bination with Direct Push (DP) soil gas concentration measurements, with the main objective being the char-acterization of an assumed permeable fault structure which is covered by sediments that are over $20 \mathrm{~m}$ thick. Geophysical methods were used to locate a potential fault zone and to provide an insight into the structural features of the covering sediments. Methods for quantifying the soil-gas concentration were applied to eval-uate the permeability of the fault zone. The positioning of gas sampling points was based on results of a geo-physical survey undertaken beforehand. Gas sampling was performed using DP-technology to obtain concentration profiles for the inert gas Radon-222 and its carrier gas $\mathrm{CO}_{2}$ along the profile at different depths. Joint interpretation of the spatial distribution of geogenic gases and results from the geophysical survey allowed us to produce a representative model image of the fault structure consisting of two fault branches. Based on this image, it was possible to interpret the observed gas concentration patterns.

\section{Introduction}

Zones of higher permeability (e.g. tectonic faults) can be responsible for increased fluid flow within subsurface. Identification of zones with fluid flow has been used for highlighting fault zones and their permeability (e.g. Byrdina et al., 2009; Ciotoli et al., 1999; Etiope et al., 2005). These fractured regions often act as a primary control for fluid flow into fault-hosted geothermal reservoirs. As such, fault zones are typically not easily detectable; mostly due to thick sedimentary covers. Increased technical and financial exploration risks exist, in relation to investigating their geothermal productivity. Therefore methods are required that can reliably detect and identify permeable fault zones prior to undertaking costly drilling programs, thereby reducing exploration risks for geothermal

\footnotetext{
* Corresponding author. Tel.: + 494312351059

E-mail addresses: claudia.schuetze@ufz.de (C. Schütze), thomas.vienken@ufz.de (T. Vienken), ulrike.werban@ufz.de (U. Werban), peter.dietrich@ufz.de (P. Dietrich), anthony.finizola@univ-reunion.fr (A. Finizola), carsten.leven-pfister@uni-tuebingen.de (C. Leven).

1 Tel.: +494312351382.

2 Tel.: +49 4312351989.

${ }^{3}$ Tel.: +494312351253.

${ }^{4}$ Tel.: + 33262262938206

5 Tel.: + 4970712973168 .
}

reservoirs. For this purpose, geochemical or geophysical methods are typically applied when undertaking a geological exploration, to be able to provide information about the structural setting of the host rock.

A geochemical approach that can be utilized for the delineation of fault zones is a soil-gas emanation survey. Here, soil-gas is typically sampled at the surface or in shallow depths down to $2 \mathrm{~m}$. The concentration of radon gas $\left({ }^{222} \mathrm{Rn}\right)$, as a product of the radioactive decay of uranium $\left({ }^{238} \mathrm{U}\right)$ with a half-life of 3.8 days, is determined by the abundance of its mother nuclide ${ }^{226} \mathrm{Ra}$, by migration and decay rate. The presence of carrier gases $\left(\mathrm{CO}_{2}, \mathrm{CH}_{4}\right)$ exhaled by deeper reservoirs may play a dominant role in controlling transport and redistribution of radon towards the earth's surface (Ciotoli et al., 1999; Etiope and Lombardi, 1995; Etiope et al., 2005; Walia et al., 2010; Yang et al., 2003, 2005). However, the degassing process can be influenced by several factors, e.g. geological structure within the fault, the sedimentary cover itself, groundwater level variation, and the meteorological situation (Heinicke et al., 1995; Kemski et al., 1996; Papp et al., 2008). In particular, several meter thick heterogeneous sediments or lowpermeable layers above the fractured bedrock could reduce the ability for performing a successful validation during a soil-gas emanation survey and reduce our ability to successfully delineate permeable fault zones using soil-gas sampling methods applied at ground surface level (Ciotoli et al., 1999). 


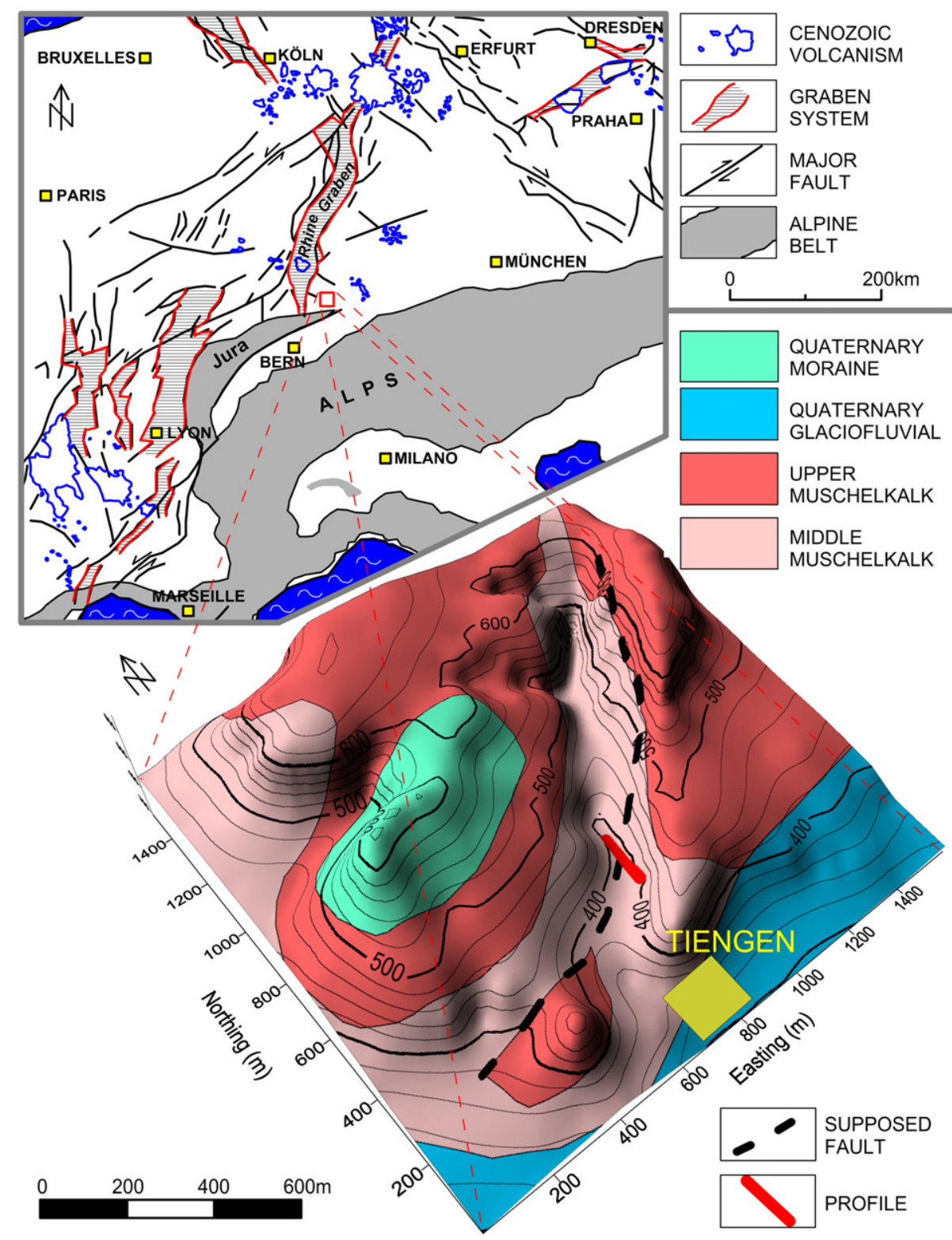

Fig. 1. General tectonic map based on Lopes Cardozo and Granet (2003) and a view of the geological situation in the vicinity of the investigation profile near the town of Tiengen in the southern Black Forest (based on general geological map; LGRB, 2006).

Geophysical methods may be able to provide an image of subsurface structural settings within the fault zone areas from a position on the near surface (Flechsig et al., 2008; McClymont et al., 2008; Tronicke et al., 2006) down to a few kilometers depth (Becken et al., 2008; Haimberger et al., 2005; Schütze et al., 2010). In particular, information on the distribution of seismic velocity and electrical resistivity can be applied to map shallow structures down to $50 \mathrm{~m}$ depth with adequate spatial resolution according to electrode/geophone spacing and alignment. In this context, the determination of resistivity anomalies is considered to be useful when investigating disturbances caused by variations in lithological parameters and fluid content (Flechsig et al. 2010; Nguyen et al., 2007; Wannamaker et al., 2004). Seismic sections have been successfully used to identify structural geological boundaries of the shallow subsurface (e.g. Giustiniani et al., 2010; Wise et al., 2003).

However, using geophysical methods alone is often insufficient for a reliable imaging of fault zones. A promising approach is the combination of geophysical methods and soil-gas analysis. Such a combination of methods has already been used for investigating volcanically or tectonically active regions (Finizola et al., 2009; Revil et al., 2004). An insight into the structural and gas-dynamic features of a hydrothermally active fault was presented by Byrdina et al. (2009) using a combination of radon and $\mathrm{CO}_{2}$ flux measurements at the surface level with geoelectrical methods. However, the application of such a combination in non-volcanic regions with characteristically low gas signals was, to our knowledge, not reported yet.

In this work, we show how a joint application of geophysical methods in combination with Direct Push (DP)-based soil-gas sampling techniques can be used for the delineation of fault zones covered by several meter thick sediments. During our investigations seismic refraction measurements were performed then followed by DC-geoelectrical measurements. DP methods were subsequently applied, to yield a further refined geophysical characterization of structures in the sediments and to obtain depth oriented soil-gas samples. The resulting geophysical images were used to select a suitable grid point for vertical DP profiling and samplings. Joint interpretation of geophysical results and determined distributions of radon and carbon dioxide concentration allowed the identification of permeable fractured zones hidden underneath sedimentary covers. 

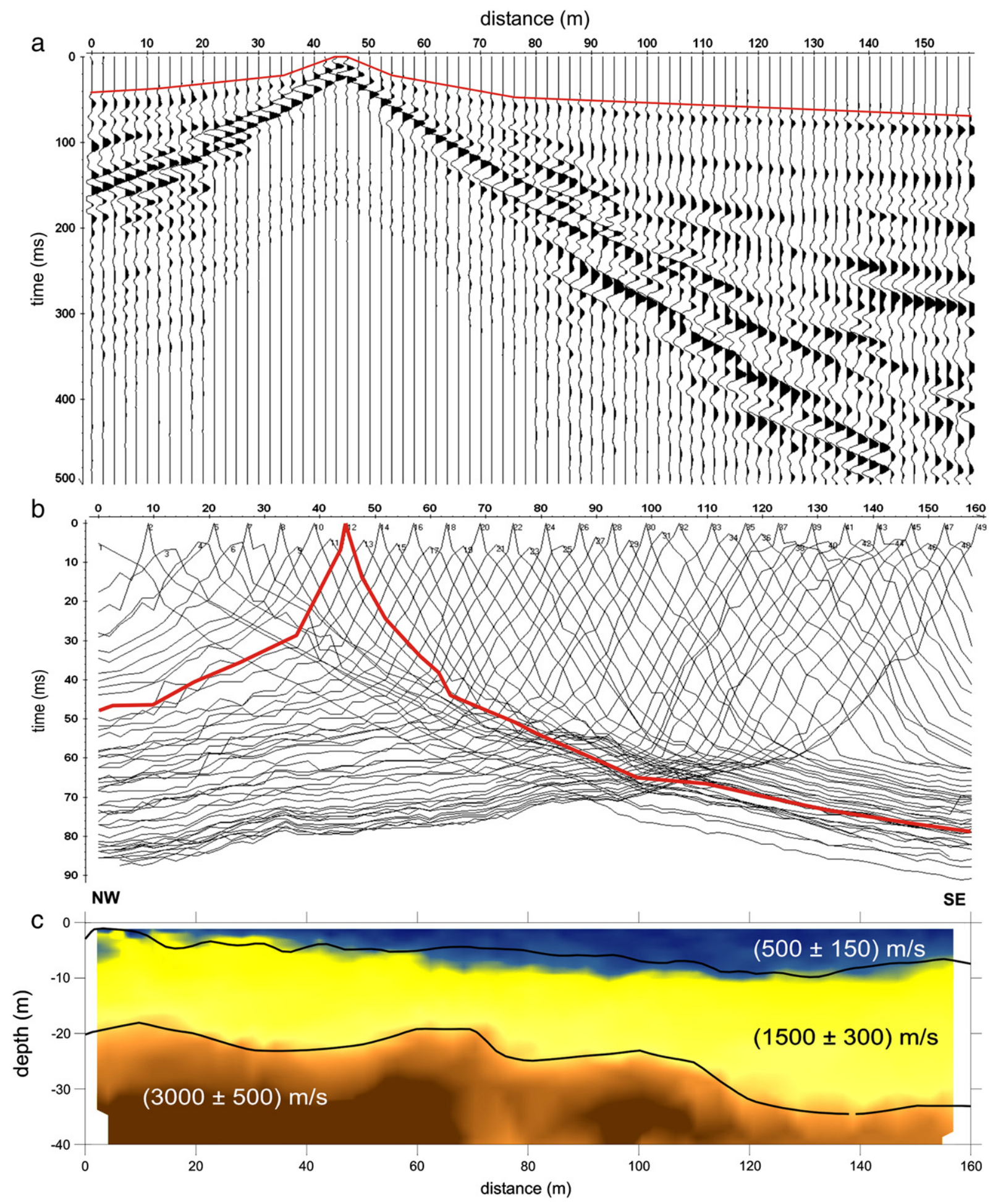

Fig. 2. a) Example of raw data obtained at shot location $x=45 \mathrm{~m}$. b) Travel times for all picked P-wave first arrivals. c) Result of seismic refraction tomography shows a three-layer P-wave velocity model. The third layer is characterized by slight vertical displacement.

\section{Geological setting}

The work described was completed within the frame of a multidisciplinary project, which aimed at developing an integrated prospection methodology concerning the investigation and evaluation of potentially enhanced geothermal systems (EGS) reservoirs within the Variscian basement in general.
The general setting of the northwestern Alpine foreland can be described as largely resulting from the interaction that took place between extensional and collosional tectonics in early Cenocoic times (Fig. 1). Currently, the southern part of the Upper Rhine Graben and adjacent regions are characterized by increased seismicity (Ustaszewski and Schmid, 2007). Seismic data shows evidence of active faulting in the basement underneath the detachment of the Jura 


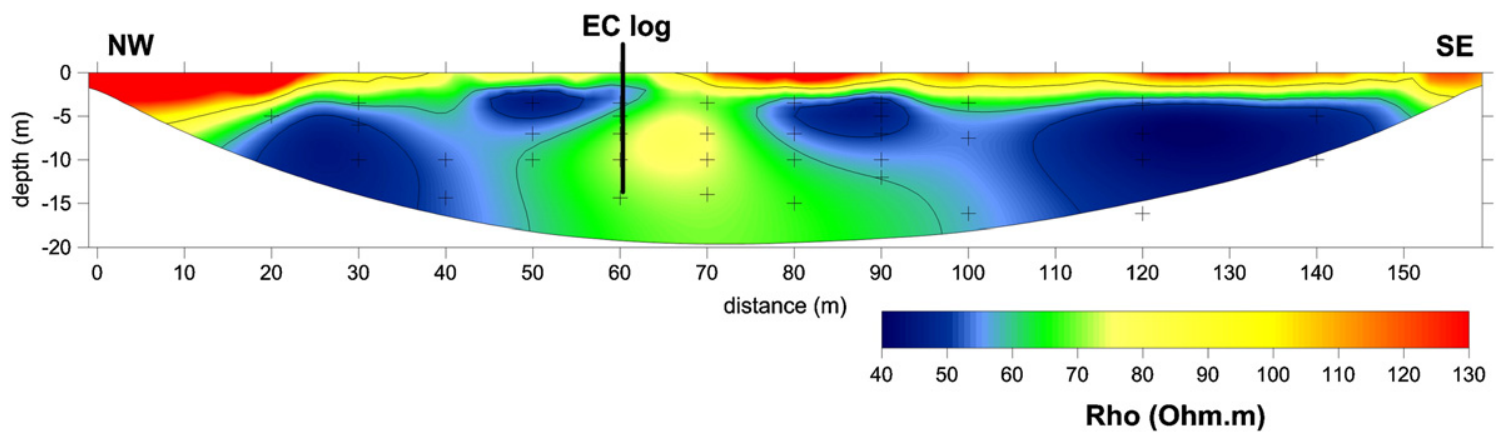

Fig. 3. Resistivity distribution model calculated from combined Wenner-alpha and Wenner-beta measurements. EC log was measured at the location $\mathrm{x}=60 \mathrm{~m}$. Soil-gas sampling points along the profile were selected based on the results of geophysical measurements ("+").

Mountains. These faults, which are interpreted as reactivated PermoCarboniferous troughs, coincide with the frontal thrusts of the Jura Mountains (Lopes Cardozo and Granet, 2003).

The major study area is the southern part of the Black Forest (Germany). This area is a typical low mountain range of the Variscian basement and forms the eastern shoulder of the Upper Rhine graben system. The geothermal potential of the southern Black Forest is well documented due to the surface heat flow, which reveals an anomaly of up to $140 \mathrm{~mW} / \mathrm{m}^{2}$ in the Waldshut-Tiengen area (Medici and Rybach, 1995), next to the Swiss border. It is assumed that this area is controlled by fault zones, which provide pathways for deep circulation. A set of regional parallel WNW-ESE striking fault zones (Eggberg, Vorwald and Zurzach) can be traced from the surface in the Black Forest to the northern part of Switzerland.

The prevailing local geological situation in the Tiengen area is sketched in Fig. 1, and can be characterized as being made up of Triassic Middle Muschelkalk (dolomitic marls, gypsum, and anhydrite)

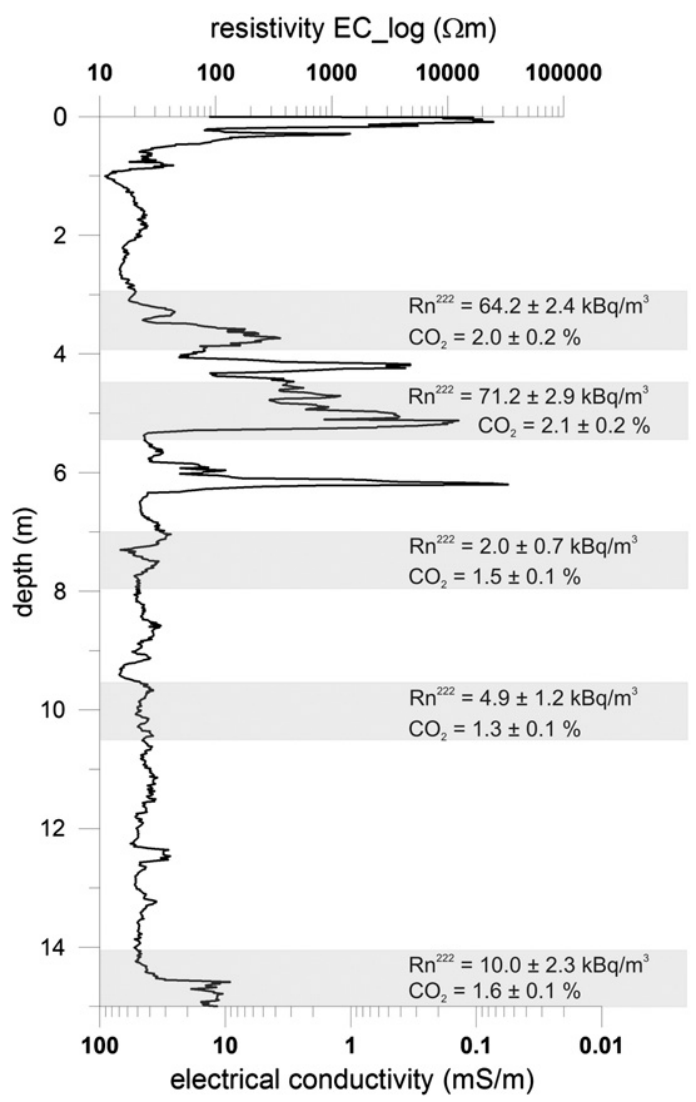

Fig. 4. $\mathrm{EC} \log$ result at $\mathrm{x}=60 \mathrm{~m}$ with low conductive horizons embedded in clayey conductive layers, in comparison with measured radon and $\mathrm{CO}_{2}$ soil-gas concentrations in 5 depth horizons. and Upper Muschelkalk layers (limestone), and local shallow Quaternary sediments that cover the Upper Bundsandstein and the basement. The Muschelkalk is known to act as a karstified aquifer. All DP drillings during the campaign carried out along the profile yielded quarried clayey and marl rich sediments. Groundwater was not found to be present. A distinct tectonic fault zone, perpendicularly aligned to the main fault system, is documented (LGRB, 2006) and is traceable at some points in the field, due to subtle topographic scarps.

The profile location for the study was aligned perpendicularly with respect to the supposed fault zone location and under the constraints of relief and infrastructural facilities (streets, power lines, agricultural use).

\section{Geophysical data}

We applied geophysical methods that can provide information about the location of the supposed fault zone and about structures in overlying sediments. Refraction seismic measurements were carried out to delineate the possible fault zone by identifying deformed refractor horizons which would indicate the presence of a fault structure (Wise et al., 2003). Tomographic interpretation of seismic refraction data offers the possibility of obtaining an insight into functions of the overlying layers. To achieve further improved images of the setting of the overlying sediments, surface geoelectrical measurements were additionally carried out. Resistivity anomalies are often related to changes in clay and/or pore fluid content. Thus, an image of the resistivity distribution can be used to support the selection of interesting sampling points for soil gas analysis and for interpretation of the results obtained from these measurements. In this regard, geophysical images were used in order to create a grid for the soil-gas measurements with sufficient spacing and sampling point locations in significant depths aligned along the geophysical profiles.

\subsection{Refraction seismics}

A conventional refraction seismic survey was carried out to identify the main structures. The seismic line was $158 \mathrm{~m}$ long with $80 \mathrm{P}-$ wave geophones $(14 \mathrm{~Hz})$ and $2 \mathrm{~m}$ spacing. The survey was conducted with $3 \mathrm{~m}$ shot point spacing, using an accelerated heavy weight drop of $40 \mathrm{~kg}$ with a fourfold energy stacking. Data was acquired and recorded from the 54 shots using Geometrics Geode seismic recorders. Signal processing was performed using the REFLEXW v 5.5 software (Sandmeier, 2010) to improve the signal-to-noise ratio including muting, bandpass filtering and picking the first breaks (Fig. 2a, b). A wavefront inversion was carried out using 3767 first P-wave travel time values in order to deduce a 2-D refractor model down to a depth of $40 \mathrm{~m}$ below surface level. The estimated model shows a typical three layer situation (shown in Fig. 2c) with a mean travel time approximation error of $3 \mathrm{~ms}$. The overburden is characterized by a mean slow P-wave velocity of less than $500 \mathrm{~m} / \mathrm{s}$, while the 


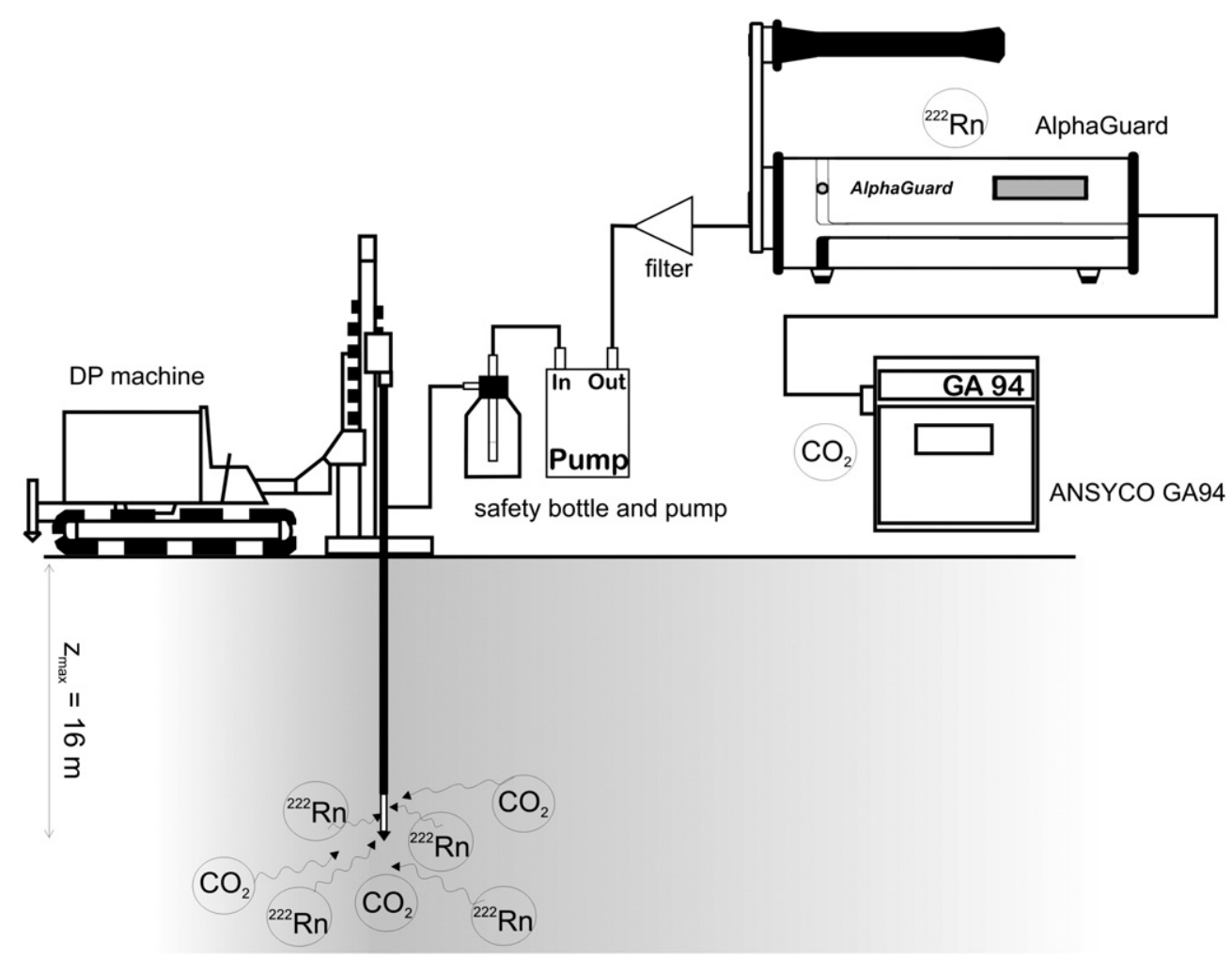

Fig. 5. Sketch of the Direct Push technology applied for depth-oriented soil-gas sampling. The data acquisition is performed using an AlphaGuard radon gas monitor and an ANSYCO GA94 mobile soil-gas analyzer. The devices are connected in series with the sampling point via air-tight tube system including filters.

velocity of the second layer is much higher, with mean values of $1500 \mathrm{~m} / \mathrm{s}$. A slight eastward dip is apparent. The velocity of the third layer was determined using values greater than $3000 \mathrm{~m} / \mathrm{s}$, and is assigned to the bedrock. There is also an eastward dipping with two prominent steps at distances of $80 \mathrm{~m}$ and $120 \mathrm{~m}$ respectively. This eastward dipping is consistent with the geological map, which shows a downward displacement of the Tiengen side of the fault in order to explain the juxtaposition of Middle and Upper Muschelkalk from both parts of this fault.

\subsection{Geoelectric investigations}

An electrical resistivity tomography (ERT) survey was carried out in close proximity to the seismic profile. The ERT measurements were used to provide a refined image of internal near surface structures down to a depth of $20 \mathrm{~m}$. The DC data acquisition was performed on the $158 \mathrm{~m}$ profile which consisted of 80 electrodes with 2-m electrode spacing, using the RESECS multi-electrode device (GeoServe, Germany). We measured both Wenner-alpha and Wenner-beta configurations along the profile, due to their advantageous signal-to-noise ratio for larger offsets and the requirement for vertical resolution. Apparent resistivity data obtained from the measurements ranged from 37 to $170 \Omega \mathrm{m}$ with a mean standard deviation error of 2.3\%. 1846 DC-data values were jointly inverted using the BERT-code (Boundless Electrical Resistivity Tomography (Günther et al., 2006; Rücker et al., 2006)). The final resistivity model of the subsurface down to a depth of $20 \mathrm{~m}$, shown in Fig. 3, can be characterized by resistivity variations from 40 to $130 \Omega \mathrm{m}$. The top layer features higher resistivity values up to $130 \Omega \mathrm{m}$. Conductive anomalies appear in shallow depths, at $5 \mathrm{~m}$ below ground level. Distinct conductive areas with resistivity values less than $50 \Omega \mathrm{m}$ were found, at distances between 20 and $45 \mathrm{~m}$ and at the distance of $110 \mathrm{~m}$ - end of the profile. The central part of the profile is characterized by a heterogeneous resistivity distribution with small-scale anomalies near the ground surface. In particular, higher resistivity values (70 $\Omega \mathrm{m}$ ) were observed in this region from below a depth of approx. $4 \mathrm{~m}$.

The inversion of the ERT data results in a smoothed image of the subsurface, due to the regularization of the inversion algorithm. The regularization parameter has to be chosen to fit the data within their variances using the least squares method. In the case of $2 \mathrm{D}$ inversion, a model misfit error of rms $=9.4 \%$ was achieved. Furthermore, inherent ambiguities of the geoelectrical method lead to the problem of equivalent solutions, which exist for all geoelectrical inversion schemes (Hoffmann and Dietrich, 2004). Therefore a vertical electrical conductivity profile with a high spatial resolution in the central part of the geoelectric profile at $\mathrm{x}=60 \mathrm{~m}$ was additionally acquired, to provide an enhanced verification of ERT data.

In our study, we measured an Electrical Conductivity log (EC log Geoprobe ${ }^{\circledR}$ Systems) using Direct Push technology to obtain the electrical conductivity as a function of depth (e.g. Leven et al., 2011; Schulmeister et al., 2003) (Fig. 4). DP also allows for an efficient sampling of soil gas, which was subsequently utilized as discussed in the following paragraph. The EC Log system is based on a classical Wenner array, with four poles arranged at distances of $2.5 \mathrm{~cm}$ from each other at the site of the probe. Using the EC logging tool, we were able to rapidly obtain information about the vertical variation of the rock parameter conductivity with a depth resolution of $1.5 \mathrm{~cm}$. Thus, it is possible to define zones characterized by lower conductivity values, equivalent to coarser grained and potentially more gaspermeable sediments (Fig. 4). The uppermost soil horizon and a zone between 3 and $6.5 \mathrm{~m}$ below ground exhibited low electrical conductivity. The EC log reveals sharp resistivity contrasts which cannot be resolved with the DC surface measurements, due to decreasing sensitivity with increasing investigation depth. Due to the same measurement principle, the lateral investigation depth of the EC $\log$ is also limited to decreasing sensitivities, i.e. its scope is limited to only a few centimeters from the probe into the soil. Therefore, the small electrode spacing allows the sensor to resolve only a small lateral radius around the probe (5 to $10 \mathrm{~cm}$; Beck et al., 2000). In contrast, a greater 

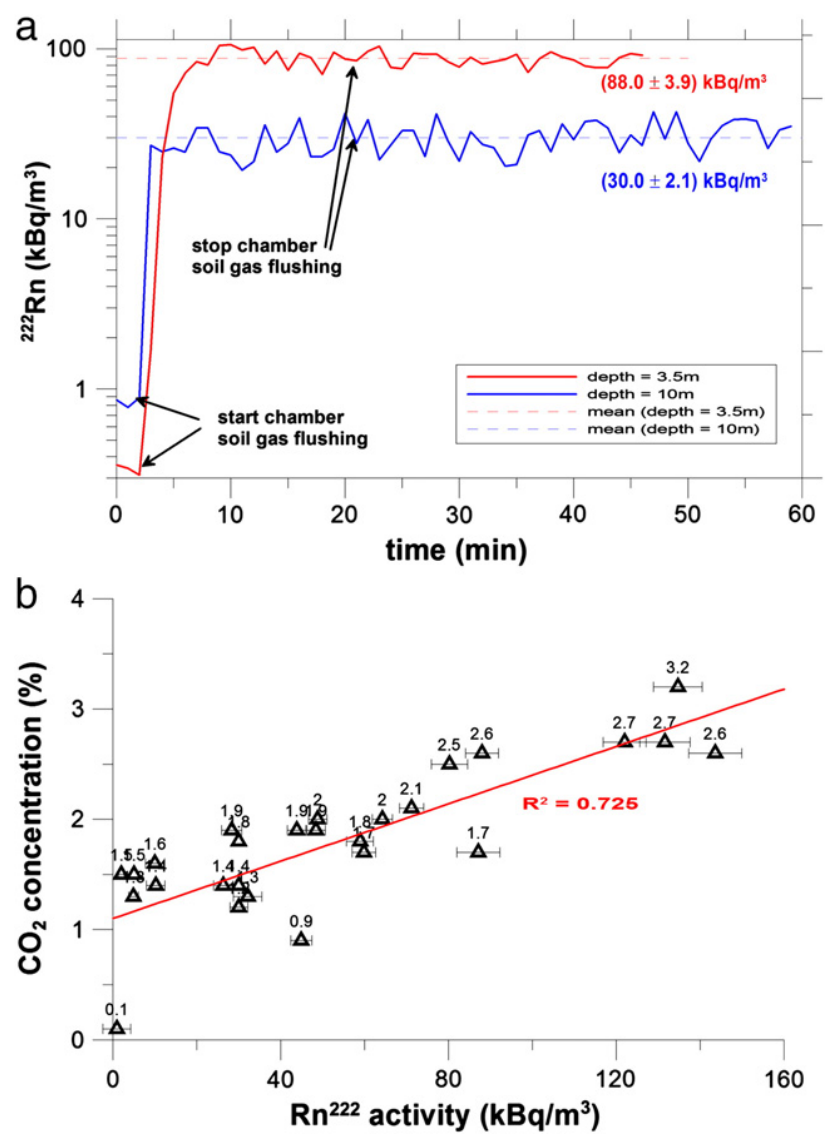

Fig. 6. a) Determination of radon gas is based on alpha particle counting as a function of time. The counting process starts after flushing of the ionization chamber with soil gas. The radon concentration is determined as a mean value at stable counting rates. This figure shows two different measurements at two sampling depths.b) Scatter plot of radon concentration versus $\mathrm{CO}_{2}$ concentration. A positive correlation with a correlation coefficient $\mathrm{R}^{2}=0.72$ was determined for $\mathrm{n}=26$ sampling points.

averaging volume (greater than 1 to $10 \mathrm{~m}^{3}$ ) causes the surface geoelectrical technique to exhibit a smoothed image of the direct-push EC $\log$ (Schulmeister et al., 2003). The lithological boundaries which are seen as sharp changes in the direct-push log, appear as gradual change in ERT imaging (Figs. 3, 4). Hence, both methods have characteristic but different fields of investigation and their results are qualitatively comparable.

\section{Soil-gas analysis}

Several meter thick sediments and the occurrence of lowly permeable layers (e.g. clayey sediments) can impede soil-gas exhalation from greater depths to the surface and can often make the detection of permeable fault zones difficult, when using shallow soil radon measurements in the standard sampling depth of approx. $1 \mathrm{~m}$. Previous work (Kemski et al., 1996) and our own first onsite test results confirmed this assumption. For this reason, we decided to use DPtechnology to circumvent the low radon signals at the surface due to the given geological situation and to additionally have the chance to characterize the spatial radon distribution as a function of depth.

For this study, depth-oriented soil-gas sampling was carried out along the profile (see Fig. 5 for a sketch of the system). Sounding locations were selected based on the results of our geophysical measurements. The soil-gas was sampled following the "whole air-active approach" (ASTM, 2006), using a Geoprobe ${ }^{\circledR}$ Post Running Tube System (PRT). The PRT uses a probe with a retractable tip that is advanced into the ground using the DP technology. Upon reaching the desired sampling depth, the probe is raised a few centimeters whilst the retractable tip was pushed out, exposing an air inlet as sampling point to the formation. The soil gas is pumped from the sampling point via a tubing system that is attached with an air-tight coupling to the sampling point. The tubing runs to a mobile AlphaGUARD Radon Monitor with an integrated gas pump. The radon monitor is based on a pulse-counting ionization chamber and is used for monitoring the radon concentration of soil gas, due to the alpha particle occurrence during the radon decay. Besides radon concentration, air temperature, pressure, and humidity were also measured.

Every measurement started and ended with fresh-air flushing of the chamber and tubes, to avoid artefacts gathering (caused by radon contaminated gas residuals). The duration of the cleaning procedure is adapted to the measured radon concentrations, which should attain values below $100 \mathrm{~Bq} / \mathrm{m}^{3}$, and typically take between 5 and $15 \mathrm{~min}$ to perform. After flushing, soil gas is pumped at a rate of $1 \mathrm{l} / \mathrm{min}$ into the AlphaGUARD chamber. An increase in radon concentration is observed in this measurement period. Once the radon concentration in the chamber is in equilibrium with the sampled soil gas, a plateau with constant concentration will be reached (Fig. 6a). At this time, the inlets and outlets of the AlphaGUARD are closed so as they are gas-tight and the actual radon concentration estimating starts. During this process, flushing procedure of the chamber with soil gas took approximately $15 \mathrm{~min}$ and the determination of radon concentration took between 20 and $60 \mathrm{~min}$.

In the sampling concept, a distance of $10 \mathrm{~m}$ for boreholes was decided upon and 5 different sampling depths (at $3 \mathrm{~m}, 5 \mathrm{~m}, 7 \mathrm{~m}, 10 \mathrm{~m}$ and $15 \mathrm{~m}$ ) were planned along the geophysical profile, situated in the vadose zone. However, at some locations sampling had to be abandoned due to insufficient soil gas yield at the envisioned sampling depths or due to the occurrence of mixing with ambient air. In such cases, an instable radon concentration curve in terms of the occurrence of very low concentration values was typical.

Migration and transportation of trace gases such as radon towards the surface is also controlled by geogenic carbon dioxide which acts as a carrier medium (Ciotoli et al., 1999; Kemski et al., 1996; Yang et al., 2005). It is important to note that the occurrence of geogenic
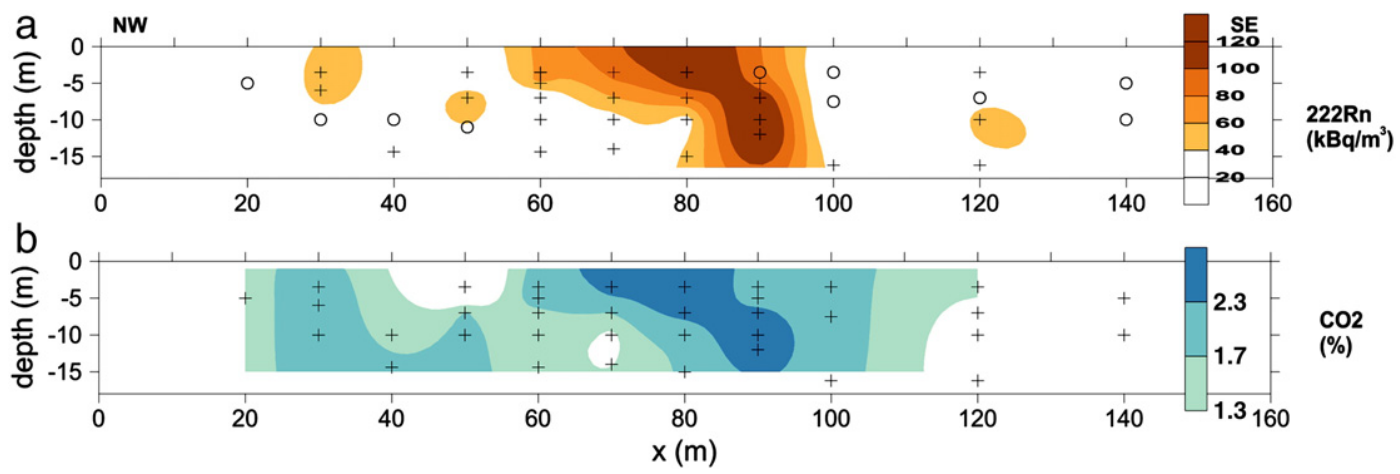

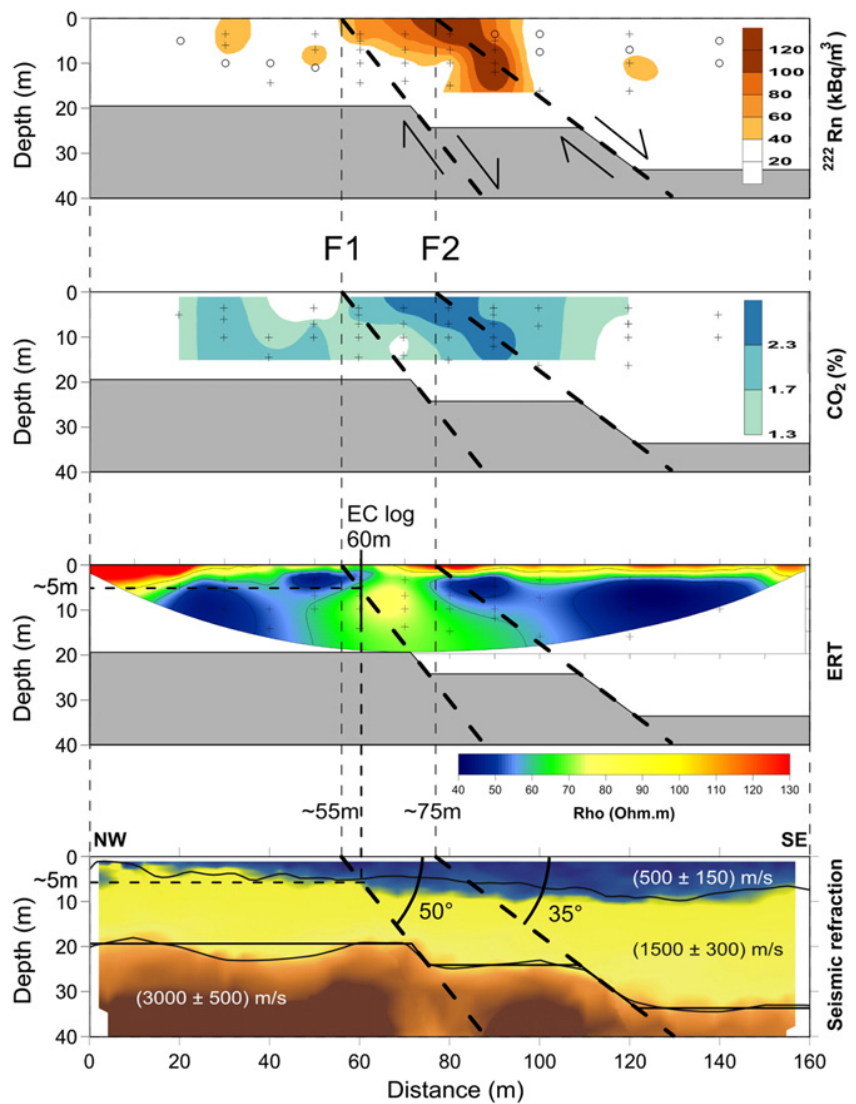

Fig. 8. Synoptical interpretation combining the geophysical and soil-gas data. Seismic refraction image suggests the presence of 2 normal faults dipping in a South Easterly direction at the basement. These two normal faults (F1 and F2) are spaced approximately $20 \mathrm{~m}$ apart at the surface level, and exhibit two different dip angles, $50^{\circ}$ and $35^{\circ}$ respectively. Both $\mathrm{CO}_{2}$ and ${ }^{222} \mathrm{Rn}$ vertical concentration maps display a higher concentration area with a clear SE dip in coincidence with the supposed fault structure.

carbon dioxide is a reliable tracer for deep fluid circulation within the fault (Walia et al., 2010). Therefore, the soil gas $\mathrm{CO}_{2}$ concentration was measured simultaneously at the radon sampling points (Fig. 5). For this purpose, an ANSYCO GA94 mobile gas analyzer was used to determine $\mathrm{CO}_{2}, \mathrm{O}_{2}$, and $\mathrm{CH}_{4}$ concentrations. This device is able to detect these targets very quickly and reliably. This analysis is based on the infrared absorption behaviour of the soil-gas compounds. Typically, a single $\mathrm{CO}_{2}$ concentration measurement takes only $30 \mathrm{~s}$ to carry out. All measured data showed distinct concentration patterns of increased $\mathrm{CO}_{2}$ values in coincidence with decreased $\mathrm{O}_{2}$ concentrations.

Finally, 26 radon sampling points with a concentration value range from $0.9 \mathrm{kBq} / \mathrm{m}^{3}$ to $143 \mathrm{kBq} / \mathrm{m}^{3}$ and a mean standard deviation of $3.3 \mathrm{kBq} / \mathrm{m}^{3}$ was obtained in 9 wells (Fig. $3 \mathrm{c}$, d). The $\mathrm{CO}_{2}$ concentration varies from $0.1 \%$ to $3.2 \%$ with a mean standard deviation of $0.2 \%$. In our study, a positive correlation between radon and $\mathrm{CO}_{2}$ concentration was observed (Fig. 6b), similar to the findings of Guerra and Lombardi (2001). The measurement of gas profiles at different locations allows identification of a gas concentration pattern (Fig. 7a, b).

\section{Joint interpretation of geophysical and gas geochemical data}

The assumption of the occurrence of a gas-bearing fault zone in the investigation area seems to be confirmed by both geophysical and soil-gas analysis. From seismic refraction imaging the transition from sedimentary overburden to the bedrock can be clearly observed, which shows a slight vertical displacement and potentially results from the suspected fault zone. The seismic refraction image suggests the presence of 2 normal faults dipping in a South Easterly direction at the basement (Fig. 8). These two normal faults (F1 and F2) are spaced approximately $20 \mathrm{~m}$ apart at the surface level, and exhibit two different dip angles, $50^{\circ}$ and $35^{\circ}$ respectively. Such a downward displacement of the SE blocks is consistent with the geology of this area (Fig. 1), and two sectors can be observed which show the contact between Upper Muschelkalk formations on the SE side of the fault and Middle Muschelkalk formations on the NW side of the fault.

As a part of this incidence of sedimentary overburden, an occurrence of resistivity anomalies is supported by DC-geoelectrical measurements, which are interpreted as sediments with high clay content. A disturbed layering sequence is evident due to the spatial pattern of the resistivity of the above anomalies. However, ERT typically presents a smooth image of the subsurface, despite its typical imaging uncertainties. In addition, the EC log provides a high resolution vertical profile of electrical resistivity and indicates that the transition from high and low resistive areas is relatively sharp.

High resistivity values in both ERT and EC log measurements can be interpreted along with data from soil-gas analysis as being subsurface areas with partly higher permeability for gas transport. Fig. 4 shows the high resolution EC log in comparison to radon concentration data from 5 different sampling depths at the same location. High radon concentrations, greater than $60 \mathrm{kBq} / \mathrm{m}^{3}$, were found in horizons with significantly lower conductivities than $10 \mathrm{mS} / \mathrm{m}$. Evaluation of the additional carrier gas indicator $\mathrm{CO}_{2}$ supports that assumption.

The measurement of gas profiles at different locations results in an image of gas concentration patterns. Reconstructed resistivity distributions can help our understanding of this pattern. Higher gas concentration values were measured, due to the abundance of more permeable coarser sediments with lower clay content coinciding with more resistive areas (Fig. 8). Considering the lack of sampling points due to probing difficulties, it seems that the highest radon concentration values are evident below zones characterized by low resistivities. This effect can be explained by accumulation processes, typical for areas below gas impermeable clayey layers. Thus, highest radon concentrations can be caused by the gas retention. Additional capture of $\mathrm{CO}_{2}$ supports the results of inert trace gas investigations. Geogenic carbon dioxide is a supporting tracer for fluid circulation within the fault and, in this case, the determined radon gas movement is linked to advection transport, using $\mathrm{CO}_{2}$ as a carrier medium. Hence, the decreased radon concentration with increasing distance from the fault can be caused by the short decay time of 3.8 days. Joint interpretation using both approaches allows a conceptual fault model to be derived. Both $\mathrm{CO}_{2}$ and ${ }^{222} \mathrm{Rn}$ vertical concentration maps display a higher concentration area with a clear SE dip in coincidence with the fault structure supposed by seismic refraction data. Consequently, a relevant structure for gas movement represented by significant geophysical and gas concentration anomalies was identified.

\section{Summary and conclusions}

This study provides an example of a successful delineation of a gasbearing fault structure, covered by several meter-thick partly clayey sediments for which a low permeability can be expected (e.g. based on Schön (2011) less than $10 \mathrm{e}^{-5} \mathrm{~m}^{2}$ ). Delineation and characterization were only made possible due to the combination of geophysical methods and soilgas sampling. Geophysical methods gave structural insights into the subsurface concerning the possible location of the fault zone, as well as information on structures in the covering sedimentary layer. Furthermore, geophysical information was used for selecting and positioning of gas sampling points. Application of DP-technology offered the possibility of obtaining gas concentration data at different depths, including for regions beneath lowly permeable sediments. The data was used for producing a concentration-depth cross-section, as well as for obtaining additional information that allowed improved interpretation of geophysical data to take place. Soil-gas emanation surveys alone, with typical sampling depths of only up to $1 \mathrm{~m}$ (maximum), would be highly susceptible to atmospheric influences. It can be expected that this would result in biased, 
vague or misleading concentration data for both radon and $\mathrm{CO}_{2}$ values, and therefore yield incorrect information concerning the location and extent of a possible fault zone.

Gas concentration mapping in greater depths and for several locations was essential, allowing for the analysis of the fault system, as well as inward migration of gases into the sediments. The geophysical results were helpful for this interpretation of observed gas concentration patterns in the sediments. The occurrence of both high radon and carbon dioxide concentrations leads to the conclusion that radon transport is linked to the migration of $\mathrm{CO}_{2}$ into the fault zone, which can be an additional indicator of fluid circulation and permeability increase. The combination of complementary methods such as the high resolution EC log, gas concentration maps as function of depth, electrical resistivity tomography and seismic refraction profile, were successfully adopted for this investigation within the frame of geothermal systems prospection, also offering potential opportunities for other applications. Consequently, joint data interpretation leads to more reliable models being derived of the investigated structures.

\section{Acknowledgement}

This research was carried out within the frame of the joint research project "EGS Technology Development" - support code 0325040B. Financial support provided by the German Federal Ministry for the Environment (BMU) is gratefully acknowledged. We would like to offer special thanks to all who gave technical assistance during the field work and to Christopher Higgins for proof reading. Furthermore, we would like to thank Dr. Heiko Woith and one anonymous reviewer for their helpful and invaluable comments.

\section{References}

ASTM International, 2006. Standard Guide for Soil-Gas Monitoring in the Vadose Zone D 5314-92, pp. 1206-1241.

Beck, F.P., Clark, P.J., Puls, R.W., 2000. Location and characterization of subsurface anomalies using a soil conductivity probe. Ground Water Monitoring \& Remediation 20, 55-59.

Becken, M., Ritter, O., Park, S.K., Bedrosian, P.A., Weckmann, U., Weber, M., 2008. A deep crustal fluid channel into the San Andreas Fault system near Parkfield, California. Geophysical Journal International 173, 718-732.

Byrdina, S., Revil, A., Pant, S.R., Koirala, B.P., Shrestha, P.L., Tiwari, D.R., Gautam, U.P. Shrestha, K., Sapkota, S.N., Contraires, S., Perrier, F., 2009. Dipolar self-potential anomaly associated with carbon dioxide and radon flux at Syabru-Bensi hot springs in central Nepal. Journal of Geophysical Research, Solid Earth 114, B10101.

Ciotoli, G. Etiope G. Guerra, M. Lombardi, S. 1999. The detection of concealed faults in the Ofanto Basin using the correlation between soil-gas fracture surveys. Tectonophysics 301, 321-332.

Etiope, G., Lombardi, S., 1995. Evidence for radon transport by carrier gas through faulted clays in Italy. Journal of Radioanalytical and Nuclear Chemistry Articles 193 (2), 291-300.

Etiope, G., Guerra, M., Raschi, A., 2005. Carbon dioxide and radon geohazards over gas-bearing fault in the Siena Graben (Central Italy). Terrestrial Atmospheric and Oceanic Sciences 16, 885-896.

Finizola, A., Aubert, M., Revil, A., Schütze, C., Sortino, F., 2009. Importance of structura history in the summit area of Stromboli during the 2002-2003 eruptive crisis inferred from temperature, soil $\mathrm{CO}_{2}$, self-potential, and electrical resistivity tomography. Journal of Volcanology and Geothermal Research 183, 213-227.

Flechsig, Ch., Bussert, R., Rechner, J., Schütze, C., Kämpf, H., 2008. The Hartoušov mofette field in the Cheb Basin, Western Eger Rift (Czech Republic): a comparative geoelectric, sedimentologic and soil gas study of a magmatic diffuse $\mathrm{CO}_{2}$-degassing structure. Zeitschrift für Geologische Wissenschaften 36, 177-193.

Flechsig, Ch., Fabig, T., Rücker, C., Schütze, C., 2010. Geoelectrical investigations in the Cheb Basin/W-Bohemia: an approach to evaluate the near-surface conductivity structure. Studia Geophysica et Geodaetica 54 (2010), 443-463.

Giustiniani, M., Tinivella, U., Acciano, F., 2010. P and S reflection and P refraction: an integration for characterising shallow subsurface. Journal of Applied Geophysics 71 149-156.
Guerra, M., Lombardi, S., 2001. Soil-gas method for tracing neotectonic faults in clay basins: the Pisticci field (Southern Italy). Tectonophysics 339 (3-4), 511-522.

Günther, Th., Rücker, C., Spitzer, K., 2006. Three-dimensional modelling and inversion of dc resistivity data incorporating topography - II. Inversion. Geophysical Journal International 166, 506-517.

Haimberger, R., Hoppe, A., Schäfer, A., 2005. High-resolution seismic survey on the Rhine River in the northern Upper Rhine Graben. International Journal of Earth Sciences 94, 657-668.

Heinicke, J., Koch, U., Martinelli, G., 1995. $\mathrm{CO}_{2}$ and Radon measurements in the Vogtland area (Germany) - a contribution to earthquake prediction research. Geophysical Research Letters 22, 771-774.

Hoffmann, R., Dietrich, P., 2004. An approach to determine equivalent solutions to the geoelectrical 2D inversion problem. Journal of Applied Geophysics 56, 79-91.

Kemski, J., Klingel, R., Siehl, A., 1996. Classification and mapping of radon-affected areas in Germany. Environmental International 22, S789-S798.

Leven, C., Weiss, H., Vienken, T., Dietrich, P., 2011. Direct Push technologies-an efficient investigation method for subsurface characterization. Grundwasser 16 (4), 221-234.

LGRB - Landesamt für Geologie, Rohstoffe und Bergbau - Regierungspräsidium Freiburg, 2006. Geologische Einheiten und Tektonik Baden-Württemberg 1:300000. www.lgrb.uni-freiburg.de/lgrb/lgrb_mapserver2006.

Lopes Cardozo, G.G.O., Granet, M., 2003. New insight in the tectonics of the southern Rhine Graben-Jura region using local earthquake seismology. Tectonics 22 (6), 1078. doi:10.1029/2002TC001442.

McClymont, A.F., Green, A.G., Streich, R., Horstmeyer, H., Tronicke, J., Nobes, D.C. Pettinga, J., Campbell, J., Langridge, R., 2008. Visualization of active faults using geometric attributes of 3D GPR data: an example from the Alpine Fault Zone, New Zealand. Geophysics 73, B11-B23.

Medici, F., Rybach, L., 1995. Geothermal Map of Switzerland 1995 (Heat flow density): Beiträge zur Geologie der Schweiz. v. Geophysik, Nr. 30.

Nguyen, F., Garambois, S., Chardon, D., Hermitte, D., Bellier, O., Jongmans, O., 2007. Subsurface electrical imaging of anisotropic formations affected by a slow active reverse fault, Provence, France. Journal of Applied Geophysics 62, 338-355.

Papp, B., Deák, F., Horváth, Á., Kiss, Á., Rajnai, G. Cs, Szabó, 2008. A new method for the determination of geophysical parameters by radon concentration measurements in bore-hole. Journal of Environmental Radioactivity 99, 1731-1735.

Revil, A., Finizola, A., Sortino, F., Ripepe, M., 2004. Geophysical investigations at Stromboli volcano, Italy. Implications for ground water flow. Geophysical Journal International 157, 426-440.

Rücker, C., Günther, Th., Spitzer, K., 2006. Three-dimensional modelling and inversion of dc resistivity data incorporating topography $-\mathrm{I}$. Modelling. Geophysical Journal International 166, 495-505.

Sandmeier, K., 2010. Reflexw manual ver. 5.5, Karlsruhe Sandmeier Scientific Software. $377 \mathrm{pp}$.

Schön, H.J., 2011. Physical properties of rocks - a workbook. Handbook of Petroleum Exploration and Production, Vol. 8. Elsevier. 481 pp.

Schulmeister, M.K., Butler, J.J., Healey, J.M., Zheng, L., Wysocki, D.A., McCall, G.W., 2003. Direct-push electrical conductivity logging for high-resolution hydrostratigraphic characterization. Groundwater Monitoring \& Remediation 23 (3), 52-62.

Schütze, C., Rücker, C., Flechsig, Ch., 2010. Large-scale geoelectrical measurements at the Central Bohemian shear zone nearby the research well Rittsteig (Bavaria, Germany). Zeitschrift für Geologische Wissenschaften 38, 69-77.

Tronicke, J., Villamor, P., Green, A.G., 2006. Detailed shallow geometry and displacement estimates of the Maleme Fault Zone, New Zealand, using 2-D and 3-D georadar. Near Surface Geophysics 4, 155-162.

Ustaszewski, K., Schmid, S.M., 2007. Latest Pliocene to recent thick-skinned tectonics at the Upper Rhine Graben-Jura Mountains junction. Swiss Journal of Geosciences 100, 293-312.

Walia, V., Lin, S.J., Fu, C.C., Yang, T.F., Hong, W.L., Wen, K.L., Chen, C.H., 2010. Soil-gas monitoring: a tool for fault delineation studies along Hsinhua Fault (Tainan), Southern Taiwan. Applied Geochemistry 25 (4), 602-607.

Wannamaker, P.E Caldwell, T.G. Doerner, W.M. Jiracek, G.R. 2004. Fault zone fluids and seismicity in compressional and extensional environments inferred from electrical conductivity: the New Zealand Southern Alps. Earth Planets Space 56, 1171-1176.

Wise, D.J., Cassidy, J., Locke, C.A., 2003. Geophysical imaging of the Quaternary Wairoa North Fault, New Zealand: a case study. Journal of Applied Geophysics 53, 1-16.

Yang, T.F., Chou, C.Y., Chen, C.H., Chyi, L.L., Jiang, J.H., 2003. Exhalation of radon and its carrier gases in SW Taiwan. Radiation Measurements 36, 425-429.

Yang, T.F., Walia, V., Chyi, L.L., Fu, C.C., Chen, C.-H., Liu, T.K., Song, S.R., Lee, C.Y., Lee, M., 2005. Variations of soil radon and thoron concentrations in a fault zone and prospective earthquakes in SW Taiwan. Radiation Measurements 40, 496-502. 